\title{
To Doors that Lead to Nowhere
}

Karyssa Nelson

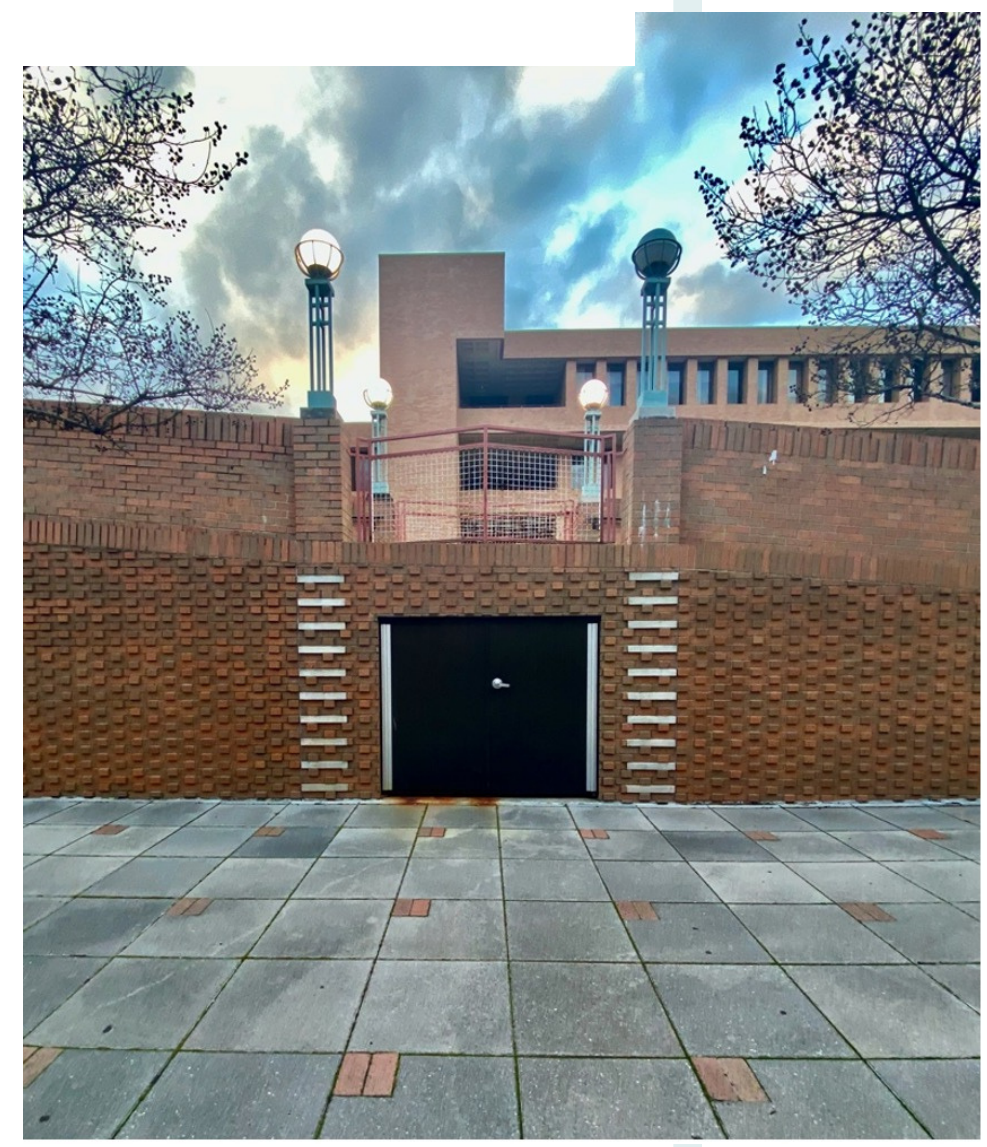

During my first day on UTA's campus in 2018, I took the same tour that each new student takes as a part of their freshman orientation. My tour guide, whilst walking backwards across the campus, pointed out a series of small doors that I likely would not have noticed otherwise. He told us that they held a sort of legacy at UTA and had become something of an inside joke between the tour guides and many of the students. These doors, positioned arbitrarily throughout the entire campus, seemingly lead nowhere. No one has ever seen a person enter or exit them; in fact, they appear to be too small to allow for anyone to make much use of them at all. And so, rumors began about the true purpose of the doors, with the most prominent one being that they lead to a series of tunnelsthat they are all interconnected, forming a secret, second campus underneath the one we know and love. But the truth is that no one will ever know where they lead, as they remain locked and largely unnoticed. Each time we passed one during my tour, however, the tour guide would distract us from whichever building we were passing by to point them out. As someone who loves learning, one of the things I hate most in this world is having a question that I know I will never know the answer to. In this reflection, I found many things in life and in medicine that find their origin in metaphorically locked doors that may lead to a number of unknown tunnels, and suddenly the tiny doors sprinkled across our campus became something else to me entirely. To this day, I am unable to pass one without wondering what lies behind it. 


\section{To doors that lead to nowhere,}

You mock me as I pass.

I glance and you stare back through me,

As I pass from class to class.

Sturdy, but unyielding,

You stay stuck to your one spot.

I long to see behind your lock,

To know what you've forgot.

I never got the chance to see What's there behind your frame.

I'm scared that if I don't ask now

I'll never have the chance again.

I've been told a labyrinth lies beneath

The ground on which I walk.

So, when no one is looking,

Perhaps I'll try to knock.

And when that fails, I'll try again-

This time, I'll pick the lock.

To doors that lead to nowhere, I fumble with my keys

A photograph, a hand-sewn dress-

Anything to appease.

I beg for you to open,

Just for a moment? Please.

I feel stupid even trying.

I feel impuissant to this disease.
So, I take a different route to class To save myself from my own blame.

But I can't stand not knowing,

And when I return, there you remain.

To doors that lead to nowhere, I tried again today.

And though I was afraid to ask, I said, "remember me?"

At first, you did not answer,

I did not expect you to.

Disappointed but accepting,

I reach out my hand to you.

I gaze down at our shadows, Intertwined, but still, separate. When suddenly, the handle moves. I hear the lock click.

You say something familiar But in a breath, the moment's passed. And all I see before me Is a blank face looking back. 